\title{
A propósito del tránsito intracelular de los virus. Comic ilustrativo.
}

A propos of the intracellular transit of viruses. Illustrative comic.

\author{
Juan Miguel Alemán-Iñiguez. ${ }^{1}$
}

\begin{abstract}
Introduction. The mechanism of how viruses cross intracellular structures is the model that exemplifies the intracellular transit through the endomembrane system, the same that is used in the teaching and description of the different intracellular apparatus and organelles. Objective. Develop a didactic method that explains a mechanism of molecular biology, such as the comic strip in the transit and intracellular signaling of viruses. Methodology. A comicillustrative story was designed where a viral structure is personified by an undercover spy, the fundamental axis of the plot is obtaining the genetic information molecules at the nucleus level, for this it has to go through the
\end{abstract}

\section{Resumen}

Introducción. El mecanismo de como los virus atraviesan las estructuras intracelulares son el modelo que ejemplifica el tránsito intracelular por el sistema de endomembranas, el mismo que es utilizado en la enseñanza y descripción de los diferentes aparatos y organelas intracelulares. Objetivo. Desarrollar un método didáctico que explique un mecanismo de la biología molecular, como lo es la tira cómica en el tránsito y la señalización intracelular de los virus. Metodología. Se diseñó una historia cómica-ilustrativa donde una estructura viral es personificada por un espía encubierto, el eje fundamental de la trama es la obtención de las moléculas de información genética a nivel del núcleo,

\footnotetext{
${ }^{1}$ Universidad San Francisco de Quito, Escuela de Posgrados Médicos, Neurocirugía, Quito, Ecuador, email (juanmig_18@hotmail.com) https://orcid.org/0000-0002-7191-9378.
} 
various departments of the cell para ello tiene que pasar por los varios representing the intracellular and departamentos de la célula que intracytoplasmic organelles with their representan las organelas intracelulares e functional characteristics, the sequence obeys the communication that the different organelles have from the cell membrane to the nucleus. Results. The development of comics or comics can recreate events and phenomena studied in medical sciences such as biology, having the following results: increase interest, understanding, creativity, the need for knowledge and generation of new ideas in students. Conclusion. The comic is a useful didactic tool in teaching intracellular transit from the graphic narration of a viral model that is transported inside the cell.

Keywords: Scaffolds, regenerative medicine, biomaterials, tissue engineering intracitoplasmáticas con sus características funcionales, la secuencia obedece a la comunicación que tienen las diferentes organelas desde la membrana celular hasta el núcleo. Resultados. La elaboración de comics o historietas pueden recrear eventos y fenómenos estudiados en las ciencias médicas como la biología, teniendo los siguientes resultados: aumentar el interés, la comprensión, la creatividad, la necesidad de conocimientos y generación de nuevas ideas en los estudiantes. Conclusión. El cómic es una herramienta didáctica útil en la enseñanza del tránsito intracelular a partir de la narración gráfica de un modelo viral que se transporta al interior de la célula.

Palabras claves: didáctica médica, sistema de endomembranas, tránsito intracelular.

\section{Introducción.}

El tránsito intracelular (TI) consiste en el paso de sustancias por diferentes mecanismos de transportes entre el sistema de endomembranas, para mantener la homeostasis y metabolismo celular ${ }^{1}$; cada organela y su membrana obedece diferentes funciones y cumple un rol en el anabolismo y catabolismo proteico, lipídico, en los glúcidos y en los ácidos nucleicos, con la participación de complejos enzimáticos específicos; estas características diferencian a cada compartimento intracelular ${ }^{2}$; la literatura tiene varios modelos para explicar la relación entre las organelas intracelulares e intracitoplasmáticas, el ejemplo más útil es el paso de las proteínas virales, ya que se caracterizan por interactuar con las endomembranas desde la membrana celular hasta la membrana nuclear, para el efecto viajan por las estructuras del citoplasma ${ }^{1,3}$. En este artículo se explica esta secuencia a través de una historieta, tira cómica o cómic interpretada por un virus, personificado por un espía encubierto y la serie de eventos moleculares explicados en una trama donde el virus intentará robar la información confidencial de una célula de la inmunidad (leucocito) ubicada a nivel nuclear; las organelas que deberá pasar, están ilustradas como las sedes de una agencia de seguridad con varios departamentos con diferentes funciones. 
Actualmente existen diferentes métodos de enseñanza y explicación de los fenómenos y eventos de las ciencias médicas, que tienen evidencia en tener beneficio y éxito en la educación médica ${ }^{4}$, en particular el cómic como instrumento didáctico puede ser útil para diseñar secuencialmente fenómenos que mejoran la comprensión, de por ejemplo la biología 5 .

\section{Metodologia.}

Se elaboro un cómic en dos versiones: español e inglés, constituido por 2 páginas, en formato blanco y negro, con diseño de siluetas de personajes y viñetas con diálogos entre ellos, los cuadros explicativos informan los escenarios y situaciones de la trama.

El Reparto está conformado por: un protagonista, el espía encubierto, que representa la proteína viral elegida por la célula para ser transportada, la organización criminal, llamada virus, a la que forma parte el espía, la estación membranosa la conforman detectives de la célula que contienen las enzimas hidrolíticas necesarias para que el virus pueda ingresar a través de las membranas sin ser fagocitado, los endosomas son otro grupo de sujetos que ayudan en el transporte directo hacia los lisosomas, que es el primer filtro del citoplasma, los ribosomas son sujetos encadenados en el sistema reticular rugoso, y son quienes le direccionan al aparato de Golgi (AG) para la obtención de la proteína G, segundo mensajero importante para transportarse por la membrana nuclear, los agentes nucleares son los últimos personajes quienes confían al espía la información genética de la agencia de la célula leucocitaria.

En cuanto a la sinopsis, lo constituyen 13 cuadros, que narran varios eventos del TI, la entrega de las enzimas hidrolíticas en la membrana celular ejemplifica la unión del virus a la membrana celular, la ayuda de los endosomas para llevar al protagonista a los lisosomas, significa el transporte por endocitosis, la llegada a los lisosomas ejemplifica como los virus burlan la fagocitosis con las proteínas hidrolíticas, el arribo al retículo endoplasmático rugoso (RER) y el encuentro con los ribosomas que redireccionan al protagonista hacia el AG significa la primera glucosilación no definitiva, en el AG, el espía encentra la segunda glucosilación definitiva del segundo mensajero que le permitirá entrar al núcleo que es la proteína G; finalmente en el interior del núcleo la información más resguardada representa a los ácidos nucleicos, el ácido desoxirribonucleico, que es alterado para afectar la codificación y síntesis proteica que finalmente permitirá la apoptosis de las células y la replicación viral, ilustrado en el cómic por la victoria de los virus.

Los escenarios de la historieta presentes son: la membrana celular, el citoplasma, los endosomas, los lisosomas, el RER, el AG y el núcleo.

Las funciones celulares a la que la historia hace referencia son: la endocitosis, la fagocitosis, primera glucosilación de las proteínas, la segunda glucosilación o definitiva de las proteínas, transporte por segundo mensajero nuclear, fosforilación y desfosforilación de los receptores de la membrana nuclear y la apoptosis inducida por virus. 


\section{Resultados.}

\section{A PROPÓSITO DEL TRÁNSITO INTRACELULAR DE LOS VIRUS. COMIC ILUSTRATIVO.}

Juan M. Alemán-Iñiguez

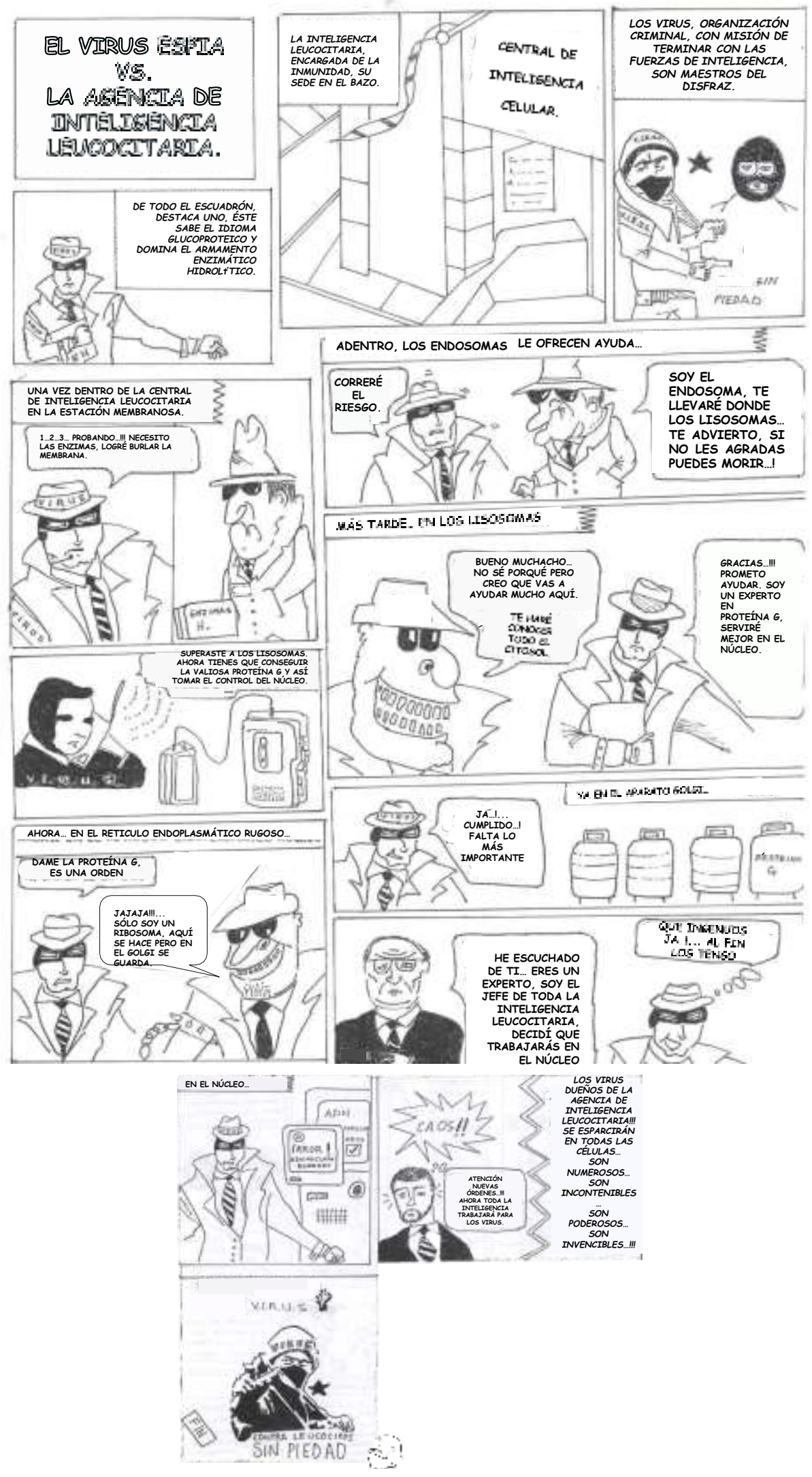




\section{À PROPOS OF THE INTRACELLULAR TRANSIT OF VIRUSES.}

\section{ILLUSTRATIVE COMIC.}

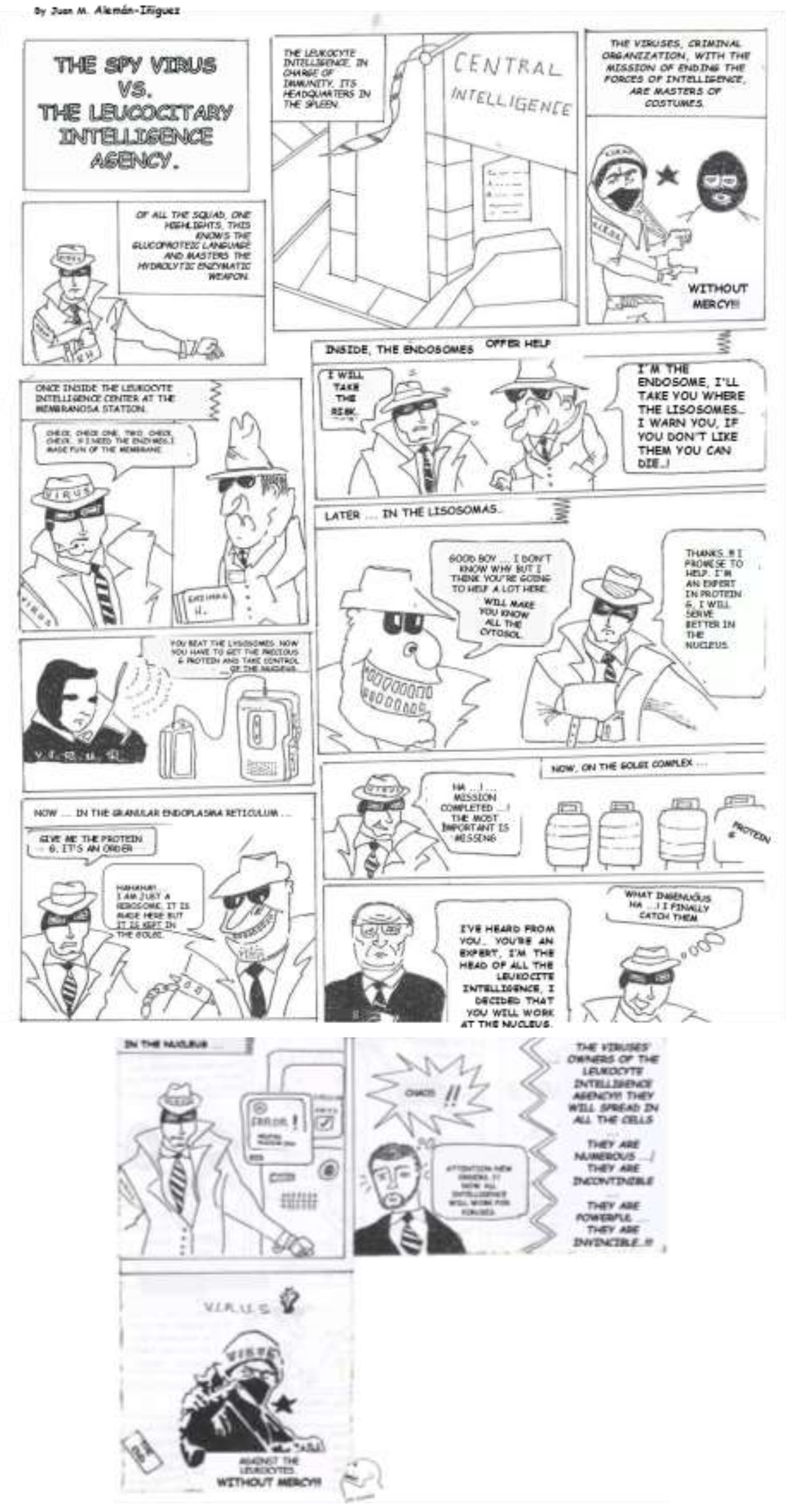




\section{Discusion.}

Las herramientas didácticas en la enseñanza de los fenómenos de las ciencias médicas más usados son: esquemas, mapas conceptuales, posters, mnemotécnicas, simuladores, recursos on-line, elementos multimedia, estrategias de aulas dinámicas, como mesas redondas o aulas invertidas y más recientemente las redes sociales, entre otros ${ }^{6}$; la validez de estos ha sido estudiada cualitativa y cuantitativamente, con variabilidad de resultados en cuanto a métodos de evaluaciones teóricas y conceptuales ${ }^{6,7}$, sin embargo las conclusiones en la mayoría han sido positivos en la percepción y el bienestar del estudiante con estos métodos ${ }^{6-9}$. El uso del arte como técnica de estudio también esta descrito, ejemplos son: el teatro, la música, el cine, la literatura y la pintura; el dibujo forma parte de este último arte y el cómic es una diversidad del dibujo y la literatura ${ }^{10-12}$.

El cómic es una representación gráfica y textual de situaciones entre personajes, que recrea una historia con diálogos en viñetas, siendo esta una forma de escritura fonética, trata de personificar interacciones entre elementos inertes, animales o personas en circunstancias de ficción o realidad; obedece a un grupo de imágenes, fotografías o pictogramas en recuadros que se articulan consecutivamente en una secuencia cronológica $^{13,14}$. La popularidad de las historietas durante la historia, desde sus primeros precursores que fueron los grafos en la aparición de la imprenta en siglo $\mathrm{XV}$, después la litografía en el siglo XVIII y hasta las primeras tiras cómicas a finales del siglo XIX e inicios del siglo XX, no solo han atraído la atención de la población infantil sino en todas las edades, hecho que hasta en nuestros tiempos no ha cambiado; son consideradas como formas de comunicación escrita y al igual que el periódico fueron usados como medios de difusión entre las masas ${ }^{12,15}$. Estas características permiten que los cómics puedan ser herramientas con objetivo comunicacional en las ciencias médicas, teniendo beneficios en atraer la atención al lector con las ilustraciones y al seguir la secuencia de imágenes que el autor propone; la información técnica es expuesta lúdicamente con la finalidad de que el estudiante pueda relacionar el conocimiento con otras funciones metales y no solo la lectura sino de manera visual y comparativa; esta descrito que el beneficio no es únicamente como herramienta de los estudiantes de medicina sino de los pacientes, incluso en otras ramas de las ciencias médica como enfermería; denominándose a esta estrategia como "la medicina gráfica"16-20.

Es conocido que los métodos de aprendizaje fundamentales tienen base en funciones mentales superiores que son: la interpretación, la traducción, la identificación, la demostración, la organización, el análisis, la catalogación, la síntesis y la ilustración son acciones que se practican cuando se elabora y lee una tira cómica en relación con una ciencia en este caso la médicina ${ }^{21}$.

El uso de tiras cómicas en biología no tiene amplia descripción si se compara a otras ciencias básicas como la anatomía ${ }^{22}$; sin embargo, se ha propuesto varias ideas en este contexto, lo que explicamos, el sistema de comunicación transmembrana de las organelas intracelulares ${ }^{23}$, no se ha realizado esta estructuración en historieta por lo que puede ser un ejemplo e incentivo a la práctica de estos métodos de aprendizaje. 


\section{Conclusiones.}

- Las cómics o historietas pueden ser una herramienta ilustrativa válida para la representación de complejas funciones de la biología molecular como lo es el tránsito y el transporte intracelular en el sistema de endomembranas; las características y estructura de una tira cómica puede ser de validez en la representación de eventos en las ciencias médicas con impacto en el aprendizaje de fenómenos científicos.

\section{Referencias bibliográficas.}

D. P. de Robertis, (2014), Biología Celular y Molecular, (Décimo sexta edición), Librería Editorial El Ateneo, Buenos Aires

Aon Miguel A., Cortassa Sonia. Function of metabolic and organelle networks in crowded and organized media. Frontiers in Physiology. 5 (2015), p523. DOI=10.3389/fphys.2014.00523

Schoelz, James \& Harries, Phillip \& Nelson, Richard. (2011). Intracellular Transport of Plant Viruses: Finding the Door out of the Cell. Molecular plant. 4. 813-31. 10.1093/mp/ssr070.

Jones, R., Higgs, R., de Angelis, C., Prideaux, D.: Changing face of medical curricula. Lancet 357(9257), 699-703 (2001).

Tatalovic, Mico. (2009). Science Comics as Tools for Science Education and Communication: A Brief, Exploratory Study. JCOM : Journal of Science Communication. 8. 10.22323/2.08040202.

Shrivastava SR, Shrivastava PS. Use of E-learning tools for assessment in medical education. Med J DY Patil Vidyapeeth 2019;12:284-5

Grunwald, Tiffany MD, MEd; Corsbie-Massay, Charisse Guidelines for Cognitively Efficient Multimedia Learning Tools: Educational Strategies, Cognitive Load, and Interface Design, Academic Medicine: March 2006 - Volume 81 - Issue 3 - p 213-223.

Ramnanan CJ, Pound LD. Advances in medical education and practice: student perceptions of the flipped classroom. Adv Med Educ Pract. 2017;8:63-73. Published 2017 Jan 13. doi:10.2147/AMEP.S109037

Back DA, Behringer F, Haberstroh N, Ehlers JP, Sostmann K, Peters H. Learning management system and e-learning tools: an experience of medical students' usage and expectations. Int J Med Educ. 2016;7:267-273. Published 2016 Aug 20. doi:10.5116/ijme.57a5.f0f5.

Ng, S.L., Baker, L., Cristancho, S., Kennedy, T.J. and Lingard, L. (2018). Qualitative Research in Medical Education. In Understanding Medical Education (eds T. 
Swanwick,

K. Forrest

and

B.C.

O'Brien). https://doi.org/10.1002/9781119373780.ch29

Torild Jacobsen Alraek \& Anders Baerheim (2005) Elements from theatre art as learning tools in medical education, Research in Drama Education: The Journal of Applied Theatre and Performance, 10:1, 5-14, DOI: 10.1080/13569780500053072

Babic, Annessa A. Comics As History, Comics As Literature: Roles of the Comic Book in Scholarship, Society, and Entertainment. Madison: Univ. Press, 2014. Print.

Postema, Barbara. Narrative Structure in Comics: Making Sense of Fragments. RIT Press, 2013. Project MUSE muse.jhu.edu/book/31439.

Cohn, Neil, author. The Visual Language of Comics : Introduction to the Structure and Cognition of Sequential Images. London ; New York :Bloomsbury Academic, An imprint of Bloomsbury Pub. Plc., 2013.

Gabilliet, Jean-Paul, Bart Beaty, and Nick Nguyen. Of Comics and Men: A Cultural History of American Comic Books. , 2013. Print.

Green M J, Myers K R. Graphic medicine: use of comics in medical education and patient care BMJ 2010; 340 :c863 doi:10.1136/bmj.c863

Goldenberg MDF. Comics: A Step toward the Future of Medicine and Medical Education? Ear, Nose \& Throat Journal. 2016;95(6):204-205. doi:10.1177/014556131609500602.

Green, M.J. Teaching with Comics: A Course for Fourth-Year Medical Students. J Med Humanit 34, 471-476 (2013). https://doi.org/10.1007/s10912-013-9245-5

Green, M.J., Myers, K., Watson, K. et al. Creativity in Medical Education: The Value of Having Medical Students Make Stuff. J Med Humanit 37, 475-483 (2016). https://doi.org/10.1007/s10912-016-9397-1

Williams ICMGraphic medicine: comics as medical narrativeMedical Humanities 2012;38:21-27.

Petranek CF, Corey S, Black R. Three Levels of Learning in Simulations: Participating, Debriefing, and Journal Writing. Simulation \& Gaming. 1992;23(2):174-185.

Koutníková, Marta. (2017). The Application of Comics in Science Education. Acta Educationis Generalis. 7. 88-98. 10.1515/atd-2017-0026.

Harries PA, Schoelz JE, Nelson RS. Intracellular transport of viruses and their components: utilizing the cytoskeleton and membrane highways. Mol Plant Microbe Interact. 2010 Nov;23(11):1381-93. doi: 10.1094/MPMI-05-10-0121. PMID: 20653412. 


\section{PARA CITAR EL ARTÍCULO INDEXADO.}

Alemán-Iñiguez, J. M. (2021). A propósito del tránsito intracelular de los virus. Comic $\begin{array}{lllll}\text { ilustrativo } \quad \text { Anatomía } & \text { Digital, } & \text { 4(4), }\end{array}$ https://doi.org/10.33262/anatomiadigital.v4i4.1886

\section{LCiencia}

El artículo que se publica es de exclusiva responsabilidad de los autores y no necesariamente reflejan el pensamiento de la Revista Anatomía Digital.

El artículo queda en propiedad de la revista y, por tanto, su publicación parcial y/o total en otro medio tiene que ser autorizado por el director de la Revista Anatomía Digital.
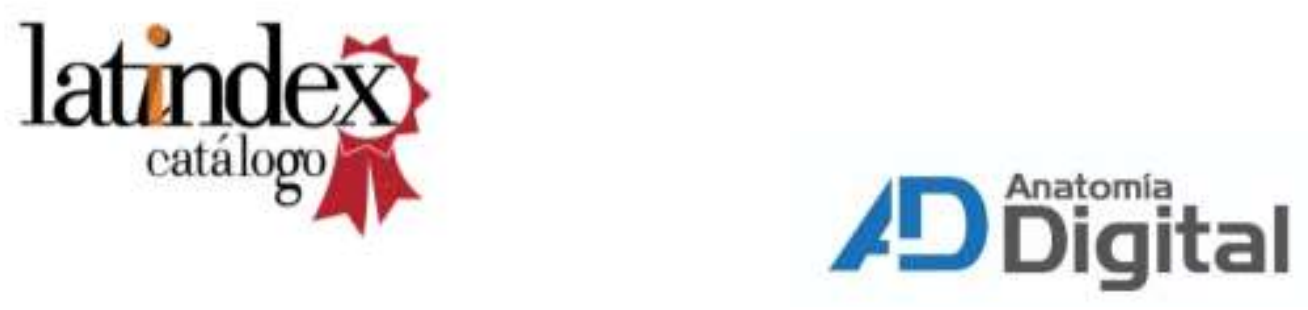